\title{
Increased serum levels of apoptosis in deficit syndrome schizophrenia patients: a preliminary study
}

This article was published in the following Dove Press journal:

Neuropsychiatric Disease and Treatment

23 May 2016

Number of times this article has been viewed

\author{
Murat Beyazyüz' \\ Tarkan Küfeciler ${ }^{2}$ \\ Leyla Bulut ${ }^{3}$ \\ Cüneyt Ünsal' \\ Yakup Albayrak' \\ Esra Soydaș Akyol ${ }^{4}$ \\ Saliha Baykal' \\ Murat Kuloglu ${ }^{5}$ \\ Kenji Hashimoto ${ }^{6}$ \\ 'Department of Psychiatry, Faculty \\ of Medicine, Namik Kemal University, \\ Tekirdag, Turkey; ${ }^{2}$ Department of \\ Emergency Medicine, Çekirge State \\ Hospital, Bursa, Turkey; ${ }^{3}$ Department \\ of Biochemistry, Okmeydani Education \\ and Research Hospital, Istanbul, \\ Turkey; ${ }^{4}$ Department of Psychiatry, \\ Yenimahalle Education and Research \\ Hospital, Ankara, Turkey; ${ }^{5}$ Department \\ of Psychiatry, Faculty of Medicine, \\ Akdeniz University, Antalya, Turkey; \\ ${ }^{6}$ Division of Clinical Neuroscience, \\ Chiba University Center for Forensic \\ Mental Health, Chiba, Japan
}

Correspondence: Yakup Albayrak Department of Psychiatry, Faculty of Medicine, Namik Kemal Universitesi Uygulama ve Arastırma Hastanesi Psikiyatri Poliklinigi Tunca Cad 100 Yil mah, Tekirdag 59100, Turkey Tel +90282505 6355434

Email dr.fuge@hotmail.com
Background: Schizophrenia is a chronic and debilitating disorder, the etiology of which remains unclear. Apoptosis is a programmed cell death mechanism that might be implicated in neuropsychiatric disorders, including schizophrenia. In this study, we aimed to compare the serum levels of apoptosis among deficit schizophrenia (DS) syndrome patients, nondeficit schizophrenia (NDS) patients, and healthy controls (HCs).

Patients and methods: After the inclusion and exclusion criteria were applied, 23 DS patients, 46 NDS patients, and 33 HCs were included in the study. The serum apoptosis levels were measured using a quantitative sandwich enzyme immunoassay with human monoclonal antibodies directed against DNA and histones.

Results: There was a significant difference among the three groups in terms of the levels of apoptosis $\left(F_{2,96}=16.58 ; P<0.001\right)$. The serum apoptosis levels in the DS and NDS groups were significantly higher than those in the HC group. Furthermore, the serum apoptosis levels in the DS group were significantly higher than the levels in the NDS group.

Conclusion: This study suggests that increased levels of apoptosis may be implicated in the pathophysiology of DS syndrome. However, further studies are needed to support the role of apoptosis in DS.

Keywords: apoptosis, etiology, deficit, psychosis

\section{Introduction}

Apoptosis is one of the most interesting mechanisms associated with the etiopathogenesis of various diseases as well as with normal aging and healthy development. In fact, it is a cell death mechanism that occurs in a programmed manner. ${ }^{1}$ Apoptosis has attracted increasing attention in recent years due to its possible role in diseases associated with the central nervous system, specifically neurodegenerative diseases and disorders. ${ }^{2}$ As neurodegeneration is a widely accepted mechanism of schizophrenia, the apoptotic mechanisms have been investigated in schizophrenia patients in both clinical and experimental studies. ${ }^{3}$

Currently, the general understanding is that the increased apoptosis levels in patients with schizophrenia and the subsequent neuronal, dendritic, and synaptic losses are due to an increased or imbalanced apoptotic mechanism. ${ }^{3}$ Other mechanisms, such as oxidative stress, glutamate excitotoxicity, and reduced neurotrophic support, are also either directly or indirectly associated with apoptosis. ${ }^{4}$ Furthermore, the reduced incidence of cancer and the reduced exposure to general cancer risks in patients with schizophrenia might support the notion of increased apoptotic mechanisms occurring in these patients. ${ }^{5,6}$ Based on such findings, researchers have suggested 
that the apoptosis levels of patients with schizophrenia warrant additional investigation. Indeed, several studies have reported some polymorphisms in the genes that are related to apoptosis, ${ }^{7-9}$ low Bcl-2 and GSK3 levels, increased Bax/ Bcl-2 ratios, increased caspase-3 activity, and higher p53 expression in patients with schizophrenia. ${ }^{10-12}$ However, in addition to the findings that support the notion of increased apoptosis, several studies have reported the downregulation of proapoptotic genes, lower number of apoptotic neurons, and decreased caspase-3 activity in patients with schizophrenia. ${ }^{13-15}$

Given that schizophrenia is a heterogeneous disorder, ${ }^{16-19}$ it is unsurprising that disputes regarding its subtyping continue, although the Diagnostic and Statistical Manual of Mental Disorders, Fifth Edition has abandoned the use of subtypes to classify the disorder. ${ }^{19}$ Since Carpenter's description of deficit schizophrenia (DS) syndrome was first published, ${ }^{20}$ studies have supported the idea that DS is a distinct form of schizophrenia. ${ }^{21}$ Further, DS seems likely to be accepted as a subtype of schizophrenia in the near future because many studies have supported the validity of this diagnosis, although it has not been mentioned in recent classification systems.

Although there have been prior studies that researched the role of apoptosis in the etiology of schizophrenia, no studies have yet compared the apoptosis levels among DS patients, nondeficit schizophrenia (NDS) patients, and healthy controls (HCs). Based on the studies that supported the classification of DS as a distinct form of schizophrenia, we aimed to investigate whether there would be a difference among the apoptosis levels of DS patients, NDS patients, and HCs. We hypothesized that the levels of apoptosis would indeed differ among these three groups.

\section{Patients and methods}

This study was conducted at the Department of Psychiatry, Kirklareli State Hospital, between January and June 2013. Patients who were diagnosed with schizophrenia according to the Diagnostic and Statistical Manual of Mental Disorders, Fourth Edition, Text Revision (DSM-IV-TR $)^{22}$ and who were regularly monitored at the research site were included in the study. The schizophrenia diagnosis was confirmed by a senior psychiatrist (YA) using the Structured Clinical Interview for $D S M-I V$ Axis $I .{ }^{23}$ The inclusion criteria for the study were as follows: diagnosis of schizophrenia, regular follow-up, age between 18 and 60 years, and volunteering to participate in the research project after receiving a detailed explanation of the study protocol. The exclusion criteria were as follows: diagnosis of a chronic medical condition, such as diabetes mellitus, cardiovascular disease, hyperlipidemia, or autoimmune disease; age $<18$ years or $>60$ years; a psychiatric diagnosis other than schizophrenia; a history of alcohol or substance dependence; a diagnosis of dementia or other neurocognitive disorder or mental retardation; a history of head trauma; extrapyramidal symptoms due to antipsychotic medication; unwillingness to be included in the study; and experiencing an exacerbation of schizophrenia.

The antipsychotic doses were converted to international chlorpromazine equivalent doses to compare the patient groups. ${ }^{24}$ The smoking status of participants was determined according to their own declarations. Moreover, the smoking status was confirmed by family members in the patient group.

After evaluating the patients according to both the inclusion and exclusion criteria, 69 patients with schizophrenia were enrolled in the study. According to the DSM-IV-TR, 35 of the enrolled patients were diagnosed with undifferentiated schizophrenia, 20 patients were diagnosed with paranoid schizophrenia, ten patients were diagnosed with residual schizophrenia, and four were diagnosed with disorganized schizophrenia. Additionally, $33 \mathrm{HCs}$ who were selected from the hospital's staff participated in the study. All HCs reported no family history of schizophrenia or other severe mental disorders.

The local ethics committee of Kirklareli State Hospital and the provincial government representatives of the Ministry of Health approved the study. All the participants stated that they understood the process of the present research and provided written informed consent. All the patients had sufficient mental capacity to understand the aims of the study and understood that the research would not affect their treatment or disease status (which is why mental retardation, dementia, other neurocognitive disorders, and the exacerbation phase of schizophrenia were among the exclusion criteria). None of the patients or their family members reported a surrogate condition. Furthermore, the families of the patients (ie, their next of kin) comprehended the study protocol after they had received detailed information concerning the study, and they also provided informed consent regarding their relatives' participation in the study.

\section{Instruments}

\section{Structured Clinical Interview for DSM-IV Axis I}

This semistructured tool was designed to diagnose any mental disorder according to the $D S M-I V-T R$ Axis I. After completing the relevant training program, any psychiatrist 
or mental health professional can apply this tool. Shortly after the Structured Clinical Interview for DSM-IV Axis I was developed by First et al, ${ }^{23}$ its validity and reliability in the Turkish language were verified. ${ }^{23-25}$

\section{Scale for the Assessment of Negative Symptoms}

Andreasen developed this scale to evaluate the level of negative symptoms in patients who were diagnosed with schizophrenia. The validity and reliability of this scale in Turkish were proven by Erkoc et al. ${ }^{26,27}$

\section{Scale for the Assessment of Positive Symptoms}

This scale was also developed by Andreasen, this time to assess the level of positive symptoms in patients with schizophrenia. The Turkish translation of this scale was reported to be valid and reliable..$^{28,29}$

\section{Schedule for Deficit Syndrome}

The patients were divided into two groups (those with DS and those without DS) using this schedule. The Schedule for Deficit Syndrome consists of four basic criteria. As the first criterion, negative symptoms, including restrictive affect, diminished emotional range, poverty of speech, curbing of interest, diminished sense of purpose, and diminished social drive, are considered. All these negative symptoms are scored between 0 and 4 . To satisfy the first criterion, patients must score 2 or more points for at least two negative symptoms. As the second criterion, two or more of the negative symptoms mentioned in the first criterion must have existed within the preceding 12 months, and must have been present during periods of clinical stability. As the third criterion, the previously mentioned negative symptoms must be primary and must not be due to anxiety, drug effect, suspiciousness, or depression. As the fourth criterion, patients must be diagnosed with schizophrenia according to the DSM-IV-TR. After assessment using the Schedule for Deficit Syndrome, the patients can be categorized according to the global categorization, which answers the question as to whether the assessed patients meet the global criteria for deficit syndrome or not. Alternatively, the patients can be assessed in terms of the severity of their symptoms, which ranged between 0 and 4 . The validity and reliability of this schedule in Turkish were established by Citak et al. ${ }^{30,31}$

\section{Brief Psychiatric Rating Scale}

This scale was developed to assess psychiatric symptoms, including negative symptoms, positive symptoms, disorganized behavior and speech, anxiety, and depression. This tool was created by Overall and Gorham and has been proven to be valid and reliable in Turkish. ${ }^{32}$

\section{Biochemical procedure Quantification of circulating nucleosomes}

The analysis was performed by a clinical biochemistry specialist (LB) who was blind to all the samples. The intensity of apoptosis in the participants was estimated by measuring the serum levels of circulating nucleosomes with a quantitative sandwich enzyme immunoassay using human monoclonal antibodies directed against DNA and histones. This method allowed for the specific detection and quantification of histone-associated DNA fragments in the mono- and oligonucleosomes (a marker for apoptotic cells) that are released into the serum. The serum levels of the nucleosomes were measured according to the manufacturer's protocol (Roche Applied Science, Indianapolis, IN, USA). Briefly put, $20 \mu \mathrm{L}$ of serum or background control was transferred into the microplate, and then $80 \mu \mathrm{L}$ of the immunoreagent cover was added to each well and covered with an adhesive foil. After incubation using an microplate shaker and gentle shaking (300 rpm) for 2 hours at $+15^{\circ} \mathrm{C}$ to $+25^{\circ} \mathrm{C}$, each well was rinsed three times with a $250-300 \mu \mathrm{L}$ incubation buffer. Next, $100 \mu \mathrm{L}$ of 2,2'-azino-bis (3-ethylbenzthiazoline-6-sulfonic acid) solution was pipetted into each well, and the microplate was incubated on a plate shaker at $250 \mathrm{rpm}$ until the color development was sufficient to perform a photometric analysis. Finally, $100 \mu \mathrm{L}$ of 2,2' -azino-bis (3-ethylbenzthiazoline6-sulfonic acid) stop solution was pipetted into each well and photometrically measured at $405 \mathrm{~nm}$. For calculation purposes, the absorbance of the samples was corrected for background fluorescence. The apoptosis values were expressed as optical density (OD).

\section{Statistical methods}

The data were analyzed using the Statistical Package for the Social Sciences, PC Version 17.0 (SPSS Inc., Chicago, IL, USA). A confidence interval of $95 \%$ and a two-tailed $P<0.025(d f=2)$ were determined to be statistically significant for all the analyses. The present study was designed to determine the differences in the levels of apoptosis between the groups. To identify the differences, an analysis of covariance (ANCOVA) test was thus used. For the primary outcome, allowing a type $1(\alpha)$ error of 0.05 , a degrees of freedom of 2 , and an effect size of 3 with a total sample size of 102 resulted in $100 \%$ power in this study. Levene's test was used to determine the homogeneity of variance, while the Kolmogorov-Smirnov test was used to determine the 
normal distribution. The $P$-values of Levene's test and the Kolmogorov-Smirnov test were found to be higher than 0.05 for all numeric variables. The differences between participants' ages were assessed using a series of one-way analyses of variance. The Tukey honest significance test was applied for the post hoc analysis of the multiple comparisons among the three groups. To assess the differences in the level of apoptosis between the groups, a general linear model was constructed. In this model, the level of apoptosis was the dependent variable, while age, sex, and smoking status were included as covariants. The Scale for the Assessment of Negative Symptoms (SANS), Scale for the Assessment of Positive Symptoms (SAPS), and Brief Psychiatric Rating Scale (BPRS) scores, the chlorpromazine equivalent dose of the antipsychotic agents and the duration of treatment were compared using Student's $t$-test. All the numerical data were expressed as mean \pm standard deviation values. The differences in sex and smoking status were assessed using the $\chi^{2}$ test. The associations among the parametric variables for each group were evaluated using Pearson's correlation test.

\section{Results}

A total of 69 patients who were diagnosed with schizophrenia and $33 \mathrm{HCs}$ were included in the present study. After assessing the patients with schizophrenia using the Schedule for Deficit Syndrome, 26 patients were included in the DS group $(37.6 \%)$ and 43 in the NDS group (62.3\%). The number of female participants in the HC group was 16 (48.5\%), while there were 24 females $(55.8 \%)$ in the NDS group and 12 $(46.2 \%)$ in the DS group. There was no significant difference in terms of sex $\left(\chi^{2}=0.72 ; P=0.69\right)$. The mean ages of the HC, NDS, and DS groups were $36.60 \pm 5.41,40.4 \pm 7.6$, and $41.15 \pm 11.0$ years, respectively. The mean ages were found to be similar among the groups $(F=2.98 ; P=0.55)$. The smoking rates were also found to be similar among the groups $\left(\chi^{2}=1.44 ; P=0.48\right)$ (Table 1$)$.

The mean SANS score was 22.9 \pm 5.9 in the NDS group and $53.3 \pm 12.7$ in the DS group. The DS group had significantly higher SANS scores than the NDS group $(t=-13.30$; $P<0.001)$. The mean SAPS scores were $25.6 \pm 10.5$ and $28.0 \pm 10.6$ in the NDS and DS groups, respectively. There was no significant difference in terms of the SAPS scores between the groups $(t=-0.88 ; P=0.37)$. The BPRS scores were $20.5 \pm 5.4$ and 28.6 \pm 5.0 in the NDS and DS groups, respectively. The BPRS scores were significantly higher in the DS group when compared with the NDS group $(t=-6.10 ; P<0.001)$. The duration of illness and the chlorpromazine equivalent doses were both found to be similar between the groups $(t=-0.03$, $P=0.9 ; t=-0.31, P=0.75$, respectively) (Table 1 ).

In general, the linear model level of apoptosis was a dependent variable, while age, sex, and smoking status were covariants. The mean levels of apoptosis were $0.23 \pm 0.03 \mathrm{OD}$ in the HC group, $0.40 \pm 0.02 \mathrm{OD}$ in the NDS group, and $0.52 \pm 0.03$ OD in the DS group. There was a significant difference among the groups in terms of the level of apoptosis $\left(F_{2,96}=16.58\right.$; $P<0.001)$. A post hoc analysis demonstrated that the level of apoptosis was significantly higher in the NDS group than in the HC group $(P=0.001)$. Further, the DS group had a significantly higher apoptosis level than the NDS and HC groups $(P=0.012$ and $P<0.001$, respectively) (Table 2). The apoptosis distributions were also presented in a dot plot (Figure 1).

A Pearson correlation analysis was separately performed to calculate the correlation between apoptosis level and age, SANS, SAPS, and BPRS scores, duration of illness, and

Table I Sociodemographic and clinical characteristics of participants

\begin{tabular}{|c|c|c|c|c|}
\hline Variables & $\begin{array}{l}\mathrm{HC} \\
(\mathrm{N}=33)\end{array}$ & $\begin{array}{l}\text { NDS } \\
(N=43)\end{array}$ & $\begin{array}{l}\text { DS } \\
(N=26)\end{array}$ & Statistic \\
\hline Age (years) & $36.6 \pm 5.4$ & $40.4 \pm 7.6$ & $4 I . I \pm I I .0$ & $F=2.98 ; P=0.055$ \\
\hline \multicolumn{5}{|l|}{ Sex } \\
\hline Female, n (\%) & $16(48.5)$ & $24(55.8)$ & $12(46.2)$ & \multirow[t]{2}{*}{$\chi^{2}=0.72 ; P=0.069$} \\
\hline Male, n (\%) & $17(5 \mid .5)$ & $19(44.2)$ & $14(53.8)$ & \\
\hline \multicolumn{5}{|l|}{ Smoking status } \\
\hline Yes, n (\%) & $16(48.5)$ & $28(65.1)$ & I5 (56.7) & \multirow[t]{2}{*}{$\chi^{2}=1.44 ; P=0.48$} \\
\hline No, n (\%) & $17(5 \mid .5)$ & I5 (34.9) & II (43.3) & \\
\hline SANS & & $22.9 \pm 5.9$ & $53.3 \pm 12.7$ & $t=-13.30 ; P<0.001$ \\
\hline SAPS & & $25.6 \pm 10.5$ & $28.0 \pm 10.6$ & $t=-0.88 ; P=0.37$ \\
\hline BPRS & & $20.5 \pm 5.4$ & $28.6 \pm 5.0$ & $t=-6.10 ; P<0.001$ \\
\hline Duration of illness (years) & - & $|7.| \pm 7 . \mid$ & $|7.2 \pm 6|$. & $t=-0.03 ; P=0.9$ \\
\hline $\begin{array}{l}\text { Cholorpromazine } \\
\text { equivalent dose }\end{array}$ & - & $348.8 \pm 176.5$ & $363.4 \pm 190.0$ & $t=-0.31 ; P=0.75$ \\
\hline
\end{tabular}

Note: Data presented as mean \pm standard deviation unless stated otherwise. Data in bold indicates statistical significance.

Abbreviations: BPRS, Brief Psychiatric Rating Scale; DS, deficit schizophrenia; HCs, healthy controls; NDS, nondeficit schizophrenia; SANS, Scale for the Assessment of Negative Symptoms; SAPS, Scale for The Assessment of Positive Symptoms; -, absent. 
Table 2 Comparison of level of apoptosis between groups

\begin{tabular}{|c|c|c|c|c|}
\hline Variable & $\begin{array}{l}\mathrm{HC} \\
(\mathrm{N}=33)\end{array}$ & $\begin{array}{l}\text { NDS } \\
(\mathrm{N}=43)\end{array}$ & $\begin{array}{l}\text { DS } \\
(N=26)\end{array}$ & Statistic \\
\hline $\begin{array}{l}\text { Level of apoptosis } \\
\text { (OD) }\end{array}$ & $0.23 \pm 0.03$ & $0.40 \pm 0.02$ & $0.52 \pm 0.03$ & $\begin{array}{l}F_{2,96}=15.38, \\
P<0.001\end{array}$ \\
\hline
\end{tabular}

Note: Data in bold indicates statistical significance.

Abbreviations: DS, deficit schizophrenia; HCs, healthy controls; NDS, nondeficit schizophrenia; OD, optical density.

chlorpromazine equivalent dose. In the NDS group, there was no significant correlation between the apoptosis level and age, SANS, SAPS, and BPRS scores, duration of treatment, and chlorpromazine equivalent dose $(r=-0.133, P=0.395$; $r=-0.012, P=0.942 ; r=0.105, P=0.509 ; r=-0.022, P=0.890$; $r=0.237, P=0.058$; and $r=-0.266, P=0.060$, respectively). However, the correlation analysis results for the DS group did not indicate a significant difference between the apoptosis level and age, SANS, SAPS, and BPRS scores, duration of illness, or chlorpromazine equivalent dose $(r=-0.339, P=0.90 ; r=0.367$, $P=0.065 ; r=0.032, P=0.876 ; r=0.012, P=0.952 ; r=0.319$, $P=0.112$; and $r=-0.258, P=0.203$, respectively) (Table 3).

\section{Discussion}

In the present study, we found that the serum apoptosis levels in schizophrenia patients with DS were significantly higher than those in the NDS and HC groups. The concept of neurodegeneration is well established in the etiology of schizophrenia. ${ }^{32-36}$ The apoptotic mechanism has also been related to this hypothesis. ${ }^{3,4}$ Numerous experimental and clinical studies have demonstrated increased apoptosis in schizophrenia. The majority of these studies investigated apoptosis in schizophrenia via the levels of Bcl-2 and its family members, and via the caspase- 3 levels. ${ }^{3,4,8,11,12,37}$ The majority of such studies supported claims regarding increased apoptosis in schizophrenia, although there are contrasting and confounding results with regard to the general concept. ${ }^{13,15}$

Schizophrenia is considered to be heterogeneous; ${ }^{16,17}$ however, the subclassification of schizophrenia remains unclear. Thus, it is difficult to research the specific biological markers of schizophrenia. Consequently, the conclusions drawn by previous studies might be somewhat speculative due to the common disregard for the heterogeneous nature of schizophrenia. Recently, increasing evidence has been found to suggest that DS is a different form of schizophrenia. ${ }^{38,39}$ This idea has been supported by studies in the biological, clinical, and sociodemographic domains. ${ }^{21}$ As a result, subgrouping patients with schizophrenia as either DS or NDS might enhance research investigating the numerous parameters of schizophrenia, as well as the knowledge base of clinicians who monitor schizophrenia patients. We suggest that subgrouping patients with schizophrenia as either DS or NDS will result in more substantial findings and conclusions
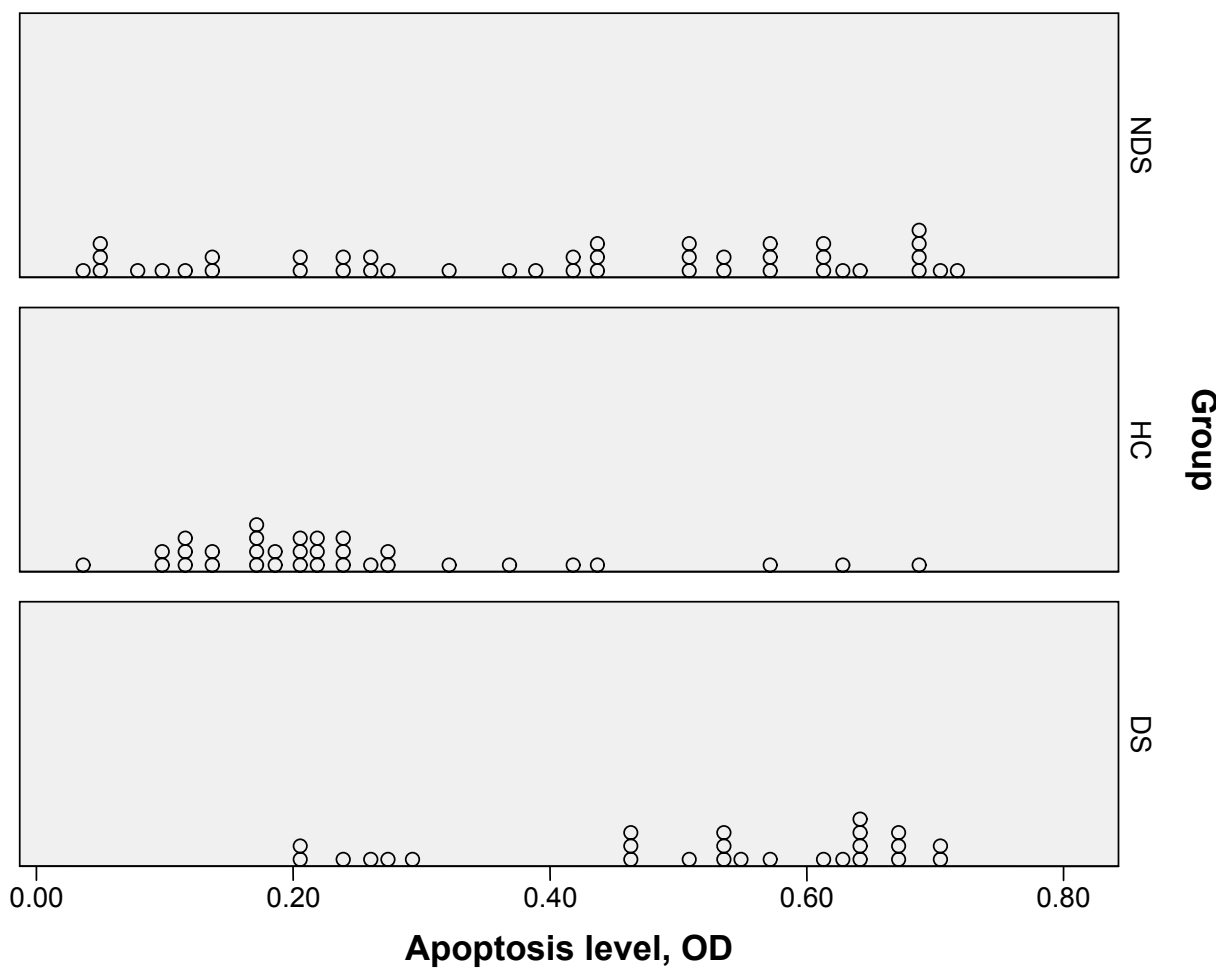

怘

Figure I Demonstration of level of apoptosis among groups with scatter dot.

Abbreviations: DS, deficit schizophrenia; HCs, healthy controls; NDS, nondeficit schizophrenia; OD, optical density. 
Table 3 Correlation coefficients between scores of level of apoptosis and age, SANS, SAPS, BPRS, duration of illness, and mean antipsychotic dose in patients

\begin{tabular}{|c|c|c|c|c|c|c|}
\hline Variables & Age & BPRS & SANS & SAPS & Duration of illness & Mean antipsychotic dose ${ }^{a}$ \\
\hline Level of apoptosis (NDS) & -0.133 & -0.012 & 0.105 & -0.022 & 0.237 & -0.266 \\
\hline Level of apoptosis (DS) & -0.339 & 0.367 & 0.032 & 0.012 & 0.319 & -0.258 \\
\hline
\end{tabular}

Note: aChlorpromazine equivalent dose.

Abbreviations: BPRS, Brief Psychiatric Rating Scale; DS, deficit schizophrenia; NDS, nondeficit schizophrenia; SANS, Scale for the Assessment of Negative Symptoms; SAPS, Scale for The Assessment of Positive Symptoms.

in this area, and it will also facilitate more targeted and focused treatments and rehabilitation.

In the literature, there have been no previous studies comparing DS and NDS patients in terms of apoptosis. As apoptosis was reported to be associated with oxidative stress $^{40-42}$ and its associated protective factors, including brain-derived neurotrophic factor (BDNF) ${ }^{43-45}$ studies have compared oxidative stress and serum BDNF levels in patients with DS and patients with NDS. We demonstrated a reduced total antioxidant potential and increased oxidative stress in DS patients when compared with the NDS and HC groups. ${ }^{46}$ Valiente-Gómez et al reported similar serum BDNF levels in patients with NDS and those with DS. ${ }^{47}$ We recently showed significantly decreased BDNF levels in patients with DS when compared with HC. ${ }^{48}$ Thus, our two previous studies indirectly supported the hypothesis of an increased apoptotic mechanism in DS patients. In the present study, we demonstrated increased levels of apoptosis in patients with DS when compared with the NDS and HC groups. Due to this finding, we can make two major speculations: first, our results support the notion that DS is a different clinical entity to NDS; and second, our results might elucidate the reason behind DS patients having a worse prognosis when compared with NDS patients. Yet, we cannot categorically determine whether the increased level of apoptosis might be associated with the phenomenology of DS, or whether it could be related to the etiological background of DS. As we found significantly increased levels of apoptosis in both schizophrenia groups when compared with the HC group, we suggest that our findings support the former presumption, namely, that high apoptosis levels are associated with the phenomenology of DS.

Our study has several limitations. First, the best method for detecting the level of apoptosis is tissue studies. However, this method is more useful in postmortem studies than in living human studies. Second, the number of participants is not large enough to draw a general conclusion. We used strict inclusion and exclusion criteria, which might explain the low number of participants. Besides the low number of participants, the power of the study was calculated as $100 \%$. We only assessed the level of apoptosis using the quantification of circulating nucleosomes method, and we were not able to investigate other apoptosis-associated markers, such as interleukins (interleukin-3 or -6), signal transducer and activator of transcription 3, Bcl-xL, or Mcl-1 gene expression. Future studies that consider the quantification of circulating nucleosome method with the other apoptosis-associated markers mentioned above will therefore be of great interest. In the present study, the patients were classified according to the existence of deficit syndrome; hence, factors such as the course of the disease or the number of acute exacerbation periods were not assessed. Evidence-based results can best be obtained from medication-naïve patients with schizophrenia. However, it is nearly impossible to design a study with medication-naïve patients and simultaneously investigate any parameter of DS patients.

Our findings suggest that increased apoptosis may be involved in the pathophysiology of DS syndrome. In particular, the disease's worse prognosis may be due to high levels of apoptosis. However, further studies are needed to support the role of apoptosis in DS schizophrenia.

\section{Acknowledgment}

The present study was not supported by any organization or funding.

\section{Author contributions}

All authors contributed toward data analysis, drafting and revising the paper and agree to be accountable for all aspects of the work.

\section{Disclosure}

The authors report no conflicts of interest in this work.

\section{References}

1. Narayanan V. Cell death in the developing nervous system, In: Hannum YA, Boustany R-M, editors. Apoptosis in Neurobiology: Concepts and Methods. Boca Raton, FL: CRC Press; 1999:Chapter 2.

2. Nishimoto I, Okamoto T, Giamberella U, Iwatsubo T. Apoptosis in neurodegenerative diseases. Adv Pharmacol. 1997;41:337.

3. Jarskog LF, Glantz LA, Gilmore JH, Lieberman JA. Apoptotic mechanisms in the pathophysiology of schizophrenia. Prog Neuropsychopharmacol Biol Psychiatry. 2005;29(5):846-858. 
4. Glantz LA, Gilmore JH, Lieberman JA, Jarskog LF. Apoptotic mechanisms and the synaptic pathology of schizophrenia. Schizophr Res. 2006; 81(1):47e63.

5. Catts VS, Catts SV, O'Toole BI, Frost AD. Cancer incidence in patients with schizophrenia and their first-degree relatives - a meta-analysis. Acta Psychiatr Scand. 2008;117(5):323-336.

6. Grinshpoon A, Barchana M, Ponizovsky A, et al. Cancer in schizophrenia: is the risk higher or lower? Schizophr Res. 2005;73(2-3):333e41.

7. Benedetti F, Poletti S, Radaelli D, et al. Temporal lobe grey matter volume in schizophrenia is associated with a genetic polymorphism influencing glycogen synthase kinase 3- $\beta$ activity. Genes Brain Behav. 2010;9(4):365-371.

8. Chen X, Sun C, Chen Q, et al. Apoptotic engulfment pathway and schizophrenia. PLoS One. 2009;4(9):e6875.

9. Yang Y, Xiao Z, Chen W, et al. Tumor suppressor gene TP53 is genetically associated with schizophrenia in the Chinese population. Neurosci Lett. 2004;369(2):126-131.

10. Jarskog LF, Gilmore JH, Selinger ES, Lieberman JA. Cortical bcl-2 protein expression and apoptotic regulation in schizophrenia. Biol Psychiatry. 2000;48(7):641-650.

11. Jarskog LF, Selinger ES, Lieberman JA, Gilmore JH. Apoptotic proteins in the temporal cortex in schizophrenia: high $\mathrm{Bax} / \mathrm{Bcl}-2$ ratio without caspase-3 activation. Am J Psychiatry. 2004;161(1):109-115.

12. Kozlovsky N, Belmaker RH, Agam G. Low GSK-3beta immunoreactivity in postmortem frontal cortex of schizophrenic patients. Am J Psychiatry. 2000;157(5):831-833.

13. Benes FM, Walsh J, Bhattacharyya S, Sheth A, Berretta S. DNA fragmentation decreased in schizophrenia but not in bipolar disorder. Arch Gen Psychiatry. 2003;60(4):359-364.

14. Benes FM, Matzilevich D, Burke RE, Walsh J. The expression of proapoptosis genes is increased in bipolar disorder but not in schizophrenia. Mol Psychiatry. 2006;11(3):241-251.

15. Catts VS, Catts SV, McGrath JJ, et al. Apoptosis and schizophrenia: a pilot study based on dermal fibroblast cell lines. Schizophr Res. 2006;84(1):20-28.

16. Eaton WW, Martins SS, Nestadt G, Bienvenu OJ, Clarke D, Alexandre P. The burden of mental disorders. Epidemiol Rev. 2008;30:1-14.

17. Tandon R, Nasrallah HA, Keshavan MS. Schizophrenia, just the facts 4 . Clinical features and conceptualization. Schizophr Res. 2009;110(1-3): $1-23$.

18. Martins-de-Souza D. Proteomics as a tool for understanding schizophrenia. Clin Psychopharmacol Neurosci. 2011;9(3):95-101.

19. American Psychiatric Association. Diagnostic and Statistical Manual of Mental Disorders. 5th ed. Washington, DC: American Psychiatric Association; 2013.

20. Carpenter WT Jr, Heinrichs D, Wagman AM. Deficit and nondeficit forms of schizophrenia: the concept. Am J Psychiatry. 1988;145(5):578-583.

21. Kirkpatrick B, Buchanan RW, Ross DE, Carpenter WT Jr. A separate disease within the syndrome of schizophrenia. Arch Gen Psychiatry. 2001;58:165-171.

22. American Psychiatric Association. Diagnostic and Statistical Manual of Mental Disorders. 4th ed. Washington, DC: American Psychiatric Association; 2000.

23. First MB, Spitzer RL, Gibbon M. Structured Clinical Interview for DSM-IV Axis I Disorders (SCID), Clinician Version. Washington, DC: American Psychiatric Press; 1996.

24. Woods SW. Chlorpromazine equivalent doses for the newer atypical antipsychotics. J Clin Psychiatry. 2003;64(6):663-667.

25. Corapcioglu A, Aydemir O, Yildiz M. Structured Clinical Interview for DSM-IV (SCID-IV), Turkish Version (Turkish). Ankara, Turkey: Hekimler Yayin Birligi; 1999.

26. Andreasen NC. Scale for the Assessment of Negative Symptoms (SANS). Iowa City, IA: College of Medicine, University of Iowa; 1984.

27. Erkoc S, Arkonaç O, Ataklı C, Ozmen E. Negatif semptomları değerlendirme ölçeğinin güvenilirliği ve geçerliliği. Düşünen Adam. 1991; 4:16-19.
28. Andreasen NC. Scale for the Assessment of Positive Symptoms (SAPS). Iowa City, IA: College of Medicine, University of Iowa; 1984.

29. Erkoc S, Arkonaç O, Ataklı C, Ozmen E. Pozitif semptomları değerlendirme ölçeğinin güvenirlirliği ve geçerliliği. Düşünen Adam. 1991; $4: 20-24$.

30. Kirkpatrick B, Buchanan RW, McKenny PD, Alphs LD, Carpenter WT Jr. The Schedule for the Deficit Syndrome: an instrument for research in schizophrenia. Psychiatry Res. 1989;30(2):119-124.

31. Citak S, Oral ET, Aker AT, Senocak M. Reliability and validity of the schedule for deficit syndrome in schizophrenia. Turk Psikiyatri Derg. 2006;17(2):115-127.

32. Overall JE, Gorham DR. The brief psychiatric rating scale. Psychol Rep. 1962;10:779-781.

33. Anderson KK, Voineskos A, Mulsant BH, George TP, Mckenzie KJ. The role of untreated psychosis in neurodegeneration: a review of hypothesized mechanisms of neurotoxicity in first-episode psychosis. Can J Psychiatry. 2014;59(10):513-517.

34. Archer T, Ricci S, Garcia D, Ricciardi MR. Neurodegenerative aspects in vulnerability to schizophrenia spectrum disorders. Neurotox Res. 2014;26(4):400-413.

35. Nurjono M, Lee J, Chong SA. A Review of brain-derived neurotrophic factor as a candidate biomarker in schizophrenia. Clin Psychopharmacol Neurosci. 2012;10(2):61-70.

36. Archer T. Neurodegeneration in schizophrenia. Expert Rev Neurother. 2010;10(7):1131-1141.

37. Gassó P, Mas S, Molina O, Lafuente A, Bernardo M, Parellada E. Increased susceptibility to apoptosis in cultured fibroblasts from antipsychotic-naïve first-episode schizophrenia patients. J Psychiatr Res. 2014;48(1):94-101.

38. Albayrak Y, Akyol ES, Beyazyüz M, Baykal S, Kuloglu M. Neurological soft signs might be endophenotype candidates for patients with deficit syndrome schizophrenia. Neuropsychiatr Dis Treat. 2015; 29(11):2825-2831.

39. Wheeler AL, Wessa M, Szeszko PR, et al. Further neuroimaging evidence for the deficit subtype of schizophrenia: a cortical connectomics analysis. JAMA Psychiatry. 2015;72(5):446-455.

40. Balu DT, Coyle JT. Neuroplasticity signaling pathways linked to the pathophysiology of schizophrenia. Neurosci Biobehav Rev. 2011; 35(3):848-870.

41. Mahadik SP, Evans D, Lal H. Oxidative stress and role of antioxidant and omega-3 essential fatty acid supplementation in schizophrenia. Prog Neuropsychopharmacol Biol Psychiatry. 2001;25(3):463-493.

42. Mukerjee S, Mahadik SP, Scheffer R, Correnti EE, Kelkar H. Impaired antioxidant defense at the onset of psychosis. Schizophr Res. 1996;19(1): 19-26.

43. McAllister AK. Neurotrophins and neuronal differentiation in the central nervous system. Cell Mol Life Sci. 2001;58(8):1054-1060.

44. Fan M, Jin W, Zhao H, et al. Lithium chloride administration prevents spatial learning and memory impairment in repeated cerebral ischemiareperfusion mice by depressing apoptosis and increasing BDNF expression in hippocampus. Behav Brain Res. 2015;29:399-406.

45. Huang X, Mao YS, Li C, Wang H, Ji JL. Venlafaxine inhibits apoptosis of hippocampal neurons by up-regulating brain-derived neurotrophic factor in a rat depression model. Pharmazie. 2014;69(12):909-916.

46. Albayrak Y, Ünsal C, Beyazyüz M, Ünal A, Kuloğlu M. Reduced total antioxidant level and increased oxidative stress in patients with deficit schizophrenia: a preliminary study. Prog Neuropsychopharmacol Biol Psychiatry. 2013;45:144-149.

47. Valiente-Gómez A, Amann BL, Mármol F, et al. Comparison of serum BDNF levels in deficit and nondeficit chronic schizophrenia and healthy controls. Psychiatry Res. 2014;15(1-2):197-200.

48. Akyol ES, Albayrak Y, Beyazyüz M, Aksoy N, Kuloglu M, Hashimoto K. Decreased serum levels of brain-derived neurotrophic factor in schizophrenic patients with deficit syndrome. Neuropsychiatr Dis Treat. 2015; $11: 865-872$ 


\section{Publish your work in this journal}

Neuropsychiatric Disease and Treatment is an international, peerreviewed journal of clinical therapeutics and pharmacology focusing on concise rapid reporting of clinical or pre-clinical studies on a range of neuropsychiatric and neurological disorders. This journal is indexed on PubMed Central, the 'PsycINFO' database and CAS,

and is the official journal of The International Neuropsychiatric Association (INA). The manuscript management system is completely online and includes a very quick and fair peer-review system, which is all easy to use. Visit http://www.dovepress.com/testimonials.php to read real quotes from published authors.

Submit your manuscript here: http://www.dovepress.com/neuropsychiatric-disease-and-treatment-journal 